\title{
Thermoelectrical characterization of new material based on PANI/zeolite HY composite, used for the detection of carbon dioxide
}

\author{
Zitouni Safidine, Zahra Ghebache and Saad Lamouri
}

In this work, conducting poly(aniline)/zeolite (PANI-HY) composites used for a carbon dioxide $\left(\mathrm{CO}_{2}\right)$ gas sensor, were prepared in two ways, The first method utilized in situ polymerization of aniline with ammonium perdisulfate as an oxidizer in an aqueous medium with addition of zeolite type HY-free acids. The second method involved the dispersion of various fractions of HY $(5,10,15,20$ and 50 wt \%) in a PANI- $\mathrm{HCl}$ matrix by physical mixing. We focused mainly on studying the conductivity with respect to temperature and gas environment. The synthesized conducting composites were characterized by FTIR, SEM, ultraviolet-visible spectroscopy, porosity and X-ray Diffraction. The PANI-HY composites showed the ability to detect $\mathrm{CO}_{2}$ at room temperature.

Polymer Journal (2013) 45, 946-954; doi:10.1038/pj.2012.232; published online 13 February 2013

Keywords: carbon dioxide gas sensor; composite; conducting polymer; conductivity; HY zeolite; PANI

\section{INTRODUCTION}

Conducting polymers are a subject of investigation for many international research groups. ${ }^{1}$ Conducting polymers have attracted much interest for their novel properties; however, their practical applicability is limited because of insolubility, infusibility and instability. Recently, interest has focused on the process ability of conducting polymers, and a number of soluble conducting polymers have been proposed. Insoluble and soluble poly(aniline) (PANI) have been studied for a long time, and both forms have potential applications as conducting polymers. ${ }^{2-4}$ PANI is one of the most commonly used conducting polymers because of its beneficial properties, such as thermal and chemical stability, controllable high electrical conductivity, low-cost and high-yield synthesis. ${ }^{5}$

The use of PANI alone is hampered by poor mechanical properties; therefore, several studies have focused on eliminating such problems by mixing PANI with various polymeric matrices (PVA, PMMA, PSS, and so on) ${ }^{6-11}$ Recently, PANI has also been dispersed in inorganic matrices. PANI/inorganic material composites have attracted great interest because of their resulting chemical, electrical and mechanical properties. $^{12}$ Among the various inorganic materials available, zeolites have been used extensively as a matrix during the last two decades. ${ }^{13}$ The resulting conducting polymer composites are used in many applications, such as electromagnetic interference shielding, ${ }^{14,15}$ gas sensors ${ }^{16-20}$ and metallic corrosion protection. ${ }^{21-24}$ This study presents the preparation of a conducting composite based on the dispersion of either PANI in a zeolite matrix or zeolite in a
PANI matrix. These new materials were also used to detect carbon dioxide $\left(\mathrm{CO}_{2}\right)$.

\section{EXPERIMENTAL PROCEDURE}

\section{Raw materials}

We utilized the following materials in this study; $\mathrm{NH}_{4}$ Yzeolite $\left[\mathrm{Na}_{1}\left(\mathrm{NH}_{4}\right)_{52}, 33\right.$ $\left.\mathrm{Al}_{53}, 33 \quad \mathrm{Si}_{138,6}{ }_{7} \mathrm{O}_{384}\right], \mathrm{SiO}_{2} / \mathrm{Al}_{2} \mathrm{O}_{3}=5.2 ; \mathrm{Na}_{2} \mathrm{O}=0.2 \%, \mathrm{Si} / \mathrm{Al}=2.6$ (Zeolyst International, Valley Forge, PA, USA). Chemical reactants: aniline monomer (Merck, Darmstadt, Germany), ammonium perdisulfate (APS; Panreac, Lyon cedex, France), hydrochloric acid (Panreac, France), ammoniac (Prolabo Distributed by VWR International, Inc., West Chester, PA, USA), ethanol (Merck Germany) acetone (AnalaR Normapur Distributed by VWR International, Inc., Darmstadt, Germany) and methanol $\mathrm{CH}_{3} \mathrm{OH}$ (AnalaR Normapur Distributed by VWR International, Inc., Germany).

\section{Preparation of HY zeolite}

$\mathrm{HY}$ was prepared using $\mathrm{NH}_{4} \mathrm{Y}$, such that $2 \mathrm{~g}$ of $\mathrm{NH}_{4} \mathrm{Y}$ was heated to $500{ }^{\circ} \mathrm{C}$ at a rate of $2{ }^{\circ} \mathrm{Cmin}^{-1}$ under a nitrogen flow rate of $1 \mathrm{mls}^{-1}$.

The processing temperature steps for $\mathrm{NH}_{4} \mathrm{Y}$ are described in Figure 1 .

The main reaction that occurred after the thermal treatment of $\mathrm{NH}_{4} \mathrm{Y}$ is:

$\mathrm{NH}_{4} \mathrm{Y} \rightarrow \mathrm{HY}+\mathrm{NH}_{3} \uparrow$

After cooling, the sample appeared similar to $\mathrm{NH}_{4} \mathrm{Y}$ powder.

Synthesis of PANI/HY zeolite composite

A typical procedure for the oxidative in situ polymerization of PANI-HY composite begins with the dispersion of HY zeolite in distilled water, to which 


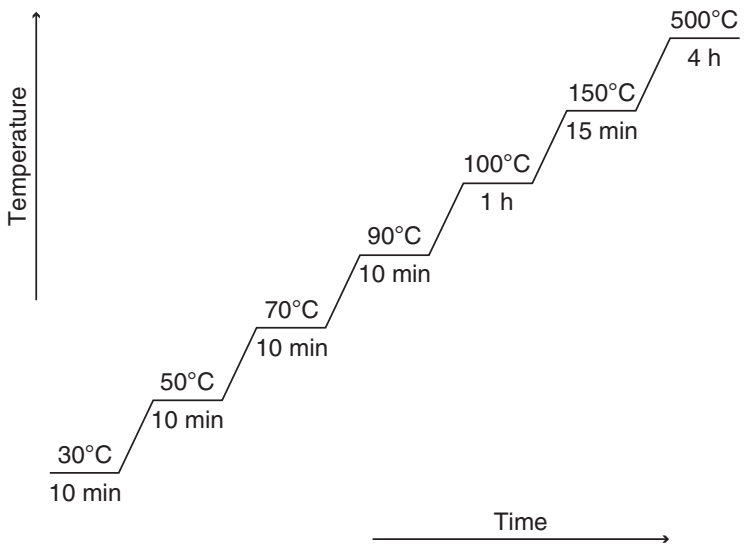

Figure 1 Temperature stages for $\mathrm{NH}_{4} \mathrm{Y}$ zeolite treatment.

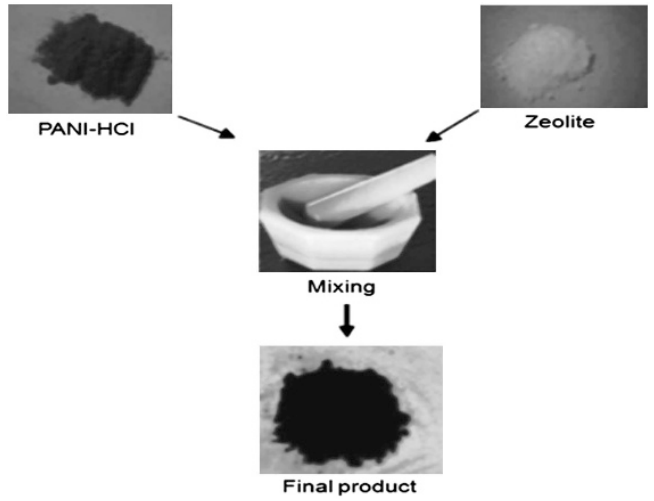

Figure 2 Flowchart for the composite preparation.

aniline was added. This suspension was stirred for $1 \mathrm{~h}$, until the solution temperature reached $0{ }^{\circ} \mathrm{C}$ or $25^{\circ} \mathrm{C}$, respectively. The oxidizing solution of APS $\left(\left(\mathrm{NH}_{4}\right)_{2} \mathrm{~S}_{2} \mathrm{O}_{8}\right)$ prepared in a ratio of concentration (oxidant)/(aniline) equal to 1.15 was added drop wise into the zeolite/aniline $(\mathrm{wt} / \mathrm{wt}=1 / 5)$. After $4 \mathrm{~h}$, the transformation of a white powder to a dark green precipitate was observed. The PANI-HY was filtered by vacuum filtration, washed several times by distilled water, and dried in vacuum for $48 \mathrm{~h}$ at $60^{\circ} \mathrm{C}$.

\section{Synthesis of PANI emeraldine salt (ES)}

PANI was synthesized by chemical oxidation of aniline, using APS $\left(\left(\mathrm{NH}_{4}\right)_{2} \mathrm{~S}_{2} \mathrm{O}_{8}\right)$ as an oxidizer and hydrochloric acid $(\mathrm{HCl})$ as a doping agent. A quantity of $4.9 \mathrm{ml}$ of aniline in $75 \mathrm{ml}$ of distilled water was mixed with $\mathrm{HCl}$. The solution temperature was held at $0{ }^{\circ} \mathrm{C}$, and then the oxidizing solution of APS $\left(\left(\mathrm{NH}_{4}\right)_{2} \mathrm{~S}_{2} \mathrm{O}_{8}\right)$ prepared at a ratio of concentration (oxidant)/(aniline) equal to 1.15 was added drop wise under continuous mechanical stirring. After $4 \mathrm{~h}$, the transformation of a white powder to a dark green precipitate was observed. The PANI- $\mathrm{HCl}$ was filtered by vacuum filtration and washed several times by distilled water and ethanol, and the resulting powder was dried in a vacuum for $48 \mathrm{~h}$ at $60^{\circ} \mathrm{C}$.

\section{Preparation of PANI ES/HY zeolite composite}

PANI- ${ }_{-1}-\mathrm{HY}$ composites were synthesized using a dry mixing method. In an agate mortar, various amounts of HY zeolite powder $(5,10,15,20$ and $50 \mathrm{wt}$ $\%)$ and $\mathrm{PANI}_{-\mathrm{HCl}}$ powder were ground together until the mixture was homogenized, as shown in Figure 2. The prepared composite powder was pressed into a disc shape using a $13 \mathrm{~mm}$ diameter stainless steel die in a hydraulic press with pressure between 3 and 4 tons. The resulting composite material was dried at $60^{\circ} \mathrm{C}$ for $48 \mathrm{~h}$. This procedure was repeated $4-5$ times, as reported elsewhere. ${ }^{25}$

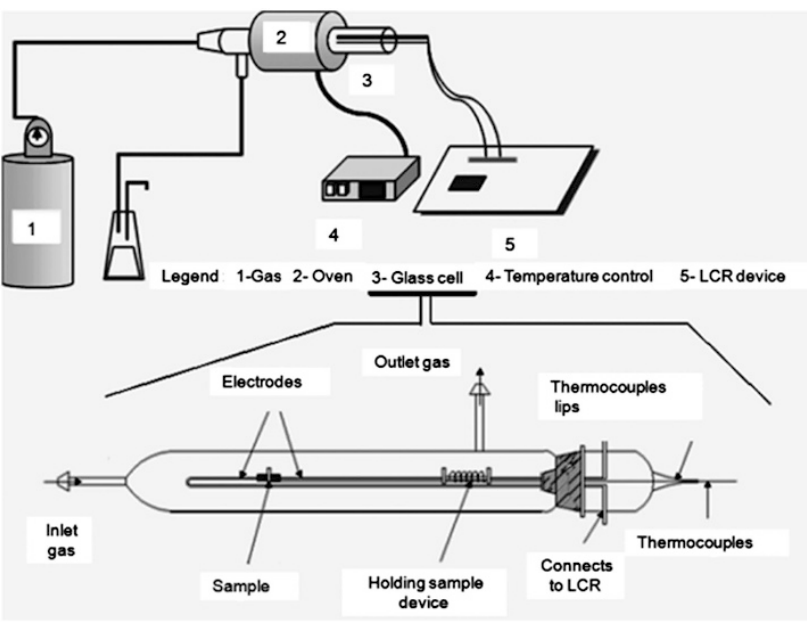

Figure 3 Schematic for conductivity measurements.

\section{Measurements}

Ultraviolet (UV)-visible spectra of the deprotonated samples dissolved in $\mathrm{N}$-methyl-2-pyrrolidone were recorded using a UV-Vis Spectrometer SHIMADZU UV-2401 (International Equipment Trading Ltd., Vernon Hills, IL, USA), in the wavelength range of $290-900 \mathrm{~nm}$. X-ray powder diffraction patterns were obtained using a 1200 HGV diffractometer (Almelo, the Netherlands). Diffraction data were collected in the $5^{\circ}-140^{\circ} 2 \theta$ region, with an increment of $0.02^{\circ}$. Nitrogen adsorption-desorption isotherms were determined using a Quantachrome Nova Surface Area Analyzer (Nova3200e, Quantachrome, Hartley Wintney, Hook, UK) at $-196^{\circ} \mathrm{C}$. The specific surface area $\left(\mathrm{S}_{\mathrm{BET}}\right)$ of each sample was calculated according to the Brunauer, Emmett and Teller method (BET) from the linear portion of the nitrogen adsorption isotherms $\left(0.05<P / P_{0}<0.35\right.$, where $P$ and $P_{0}$ are the equilibrium and saturation pressures of $\mathrm{N}_{2}$ at the temperature of adsorption, respectively). A Quanta 600 FEG scanning electron microscope (Fei Company, Eindhoven, the Netherlands) was used to characterize the morphology of the samples. FTIR spectra of PANI pellets were obtained with a SHIMADZU FTIR-8400S spectrometer (Shimadzu Europa GmbH, Duisburg, F.R. Germany) in the absorption mode, with 60 scans at a resolution of $1 \mathrm{~cm}^{-1}$, covering the wave number range between 4000 and $400 \mathrm{~cm}^{-1}$.

For electrical conductivity measurements at room temperature, the samples were pressed into pellets $(13 \mathrm{~mm}$ in diameter) using a hydraulic press at $124 \mathrm{MPa}$. The conductivity was measured with an ohmmeter LCR Data Bridge 9341 RACAL-DANA (Racal Dana instruments Ltd, Windsor Berkshire, UK) at a fixed frequency of $1 \mathrm{KHz}$, using the following equation:

$$
\sigma=\frac{e}{R \cdot \pi \cdot r^{2}}
$$

where $R$ is the resistivity $(\Omega), e$ is the thickness $(\mathrm{cm})$ and $r$ is the ray $(\mathrm{cm})$.

A novel device was implemented to measure electrical conductivity as a function of temperature. This device included a glass cell with an inlet and a purge suitable for different gases. Samples were held between two electrodes (highly conductive metal discs) and exposed to different gases. The cell was connected to the LCR and was heated by an oven; another device monitored the temperature of the oven and controlled its heating rate. The measurement scheme is illustrated in Figure 3.

\section{RESULTS AND DISCUSSION}

The mechanism of oxidative polymerization of aniline with APS in aqueous zeolite HY suspensions without adding acid has been described by Marjanovic et al. ${ }^{26}$ The main scheme is shown in Figure 4. 


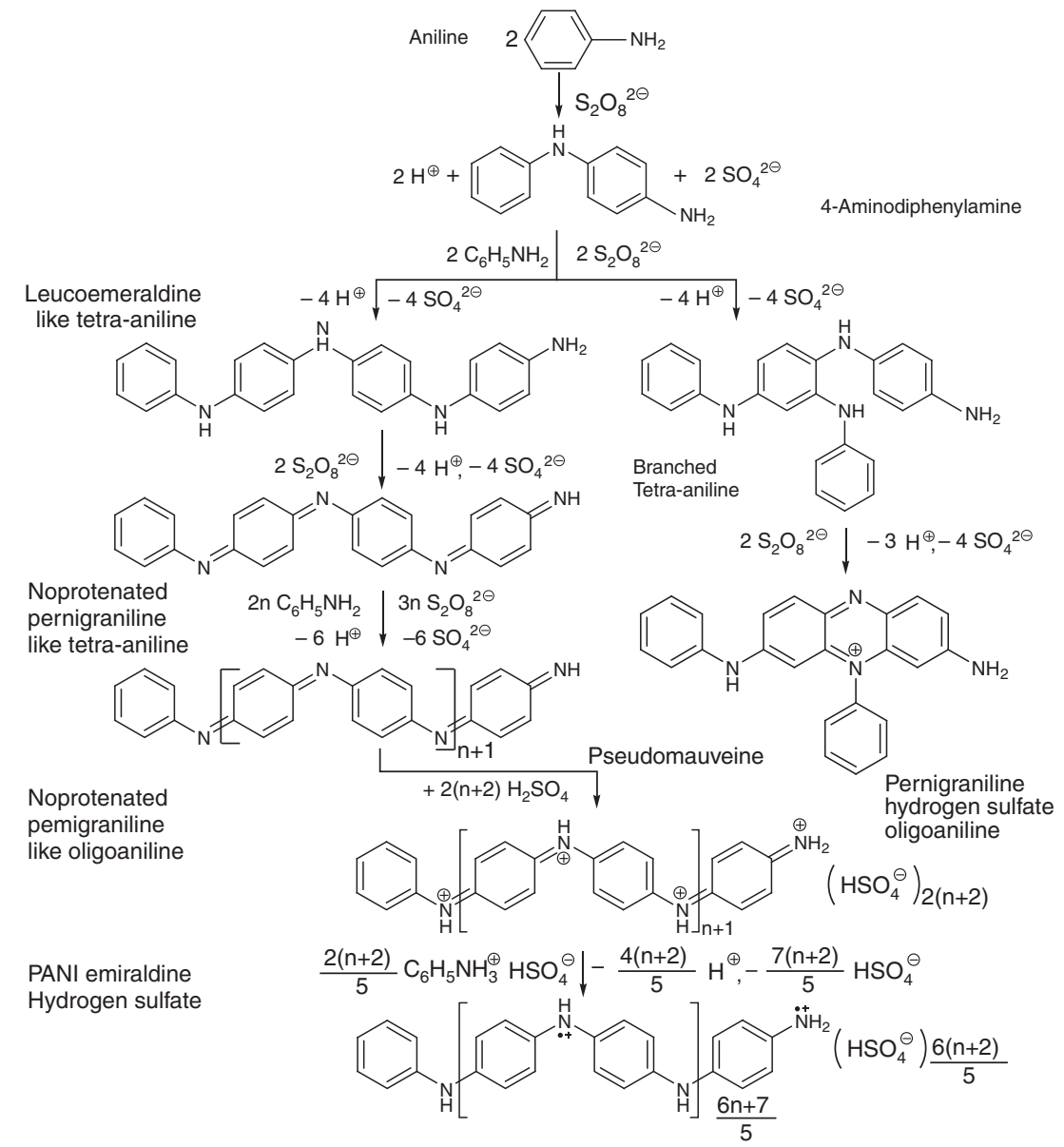

Figure 4 Mechanism of the oxidative polymerization of aniline with ammonium perdisulfate (APS), in aqueous suspension of zeolite HY.

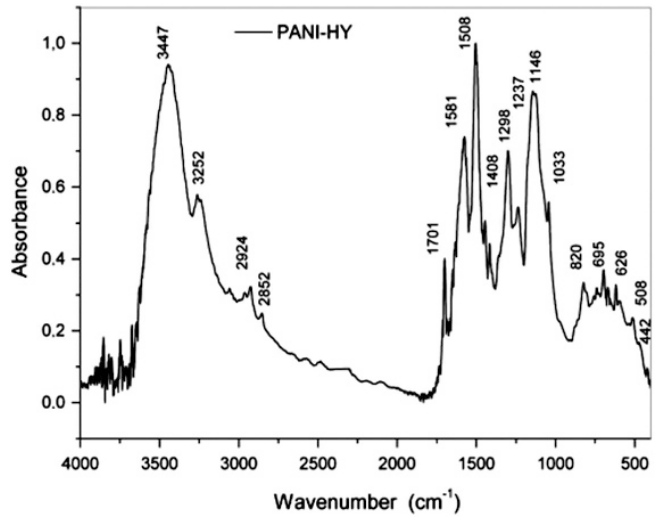

Figure 5 Infrared spectrum of poly(aniline)/zeolite (PANI-HY).

The main reaction occurring within $\mathrm{HY}$ is as follows: ${ }^{27}$

$$
\begin{aligned}
& \mathrm{HY}+\mathrm{n} \mathrm{C}_{6} \mathrm{H}_{5} \mathrm{NH}_{2} \stackrel{\mathrm{H}_{2} \mathrm{O}}{\longrightarrow}\left(\mathrm{C}_{6} \mathrm{H}_{5} \mathrm{NH}_{3}\right)_{n} \mathrm{Y} \\
& \left(\mathrm{C}_{6} \mathrm{H}_{5} \mathrm{NH}_{3}\right)_{\mathrm{n}} \mathrm{Y}+\left(\mathrm{NH}_{4}\right)_{2} \mathrm{~S}_{2} \mathrm{O}_{8} \rightarrow(\mathrm{PANI}) \mathrm{HY}
\end{aligned}
$$

\section{Infrared spectroscopy}

Figure 5 shows the FTIR spectrum of PANI-HY composite, in which significant vibrational bands are revealed. The characteristic bands that were observed from the ES are located at 3447 and $3252 \mathrm{~cm}^{-1}$ and are attributed to stretching vibrations of $\mathrm{O}-\mathrm{H}$ and $\mathrm{N}-\mathrm{H}$, respectively. ${ }^{28}$ The bands at $1581 \mathrm{~cm}^{-1}$ (quinonoid ring) and $1508 \mathrm{~cm}^{-1}$ (benzenoid ring) are related to the deformation and stretching vibrations of the $\mathrm{C}=\mathrm{C}$ bond in $(\mathrm{N}=\mathrm{Q}=\mathrm{N})$ and $\mathrm{C}-\mathrm{C}$ bond in $(\mathrm{N}-\mathrm{B}-\mathrm{N})$, respectively. These two bands are very important because they provide qualitative information regarding the oxidation behavior of PANI. The peaks at 2924 and $2852 \mathrm{~cm}^{-1}$ were assigned to stretching vibrations of $\mathrm{C}-\mathrm{H}$ bonds within the PANI structure. ${ }^{25,29}$

The characteristic bands of the zeolite at 1237 and $1033 \mathrm{~cm}^{-1}$ correspond to stretching of the $\mathrm{O}-\mathrm{T}-\mathrm{O}$ group and elongation of the early T-O-T group. ${ }^{30,31}$ Bands at 1298 and $1146 \mathrm{~cm}^{-1}$ are due to vibrations of the $\mathrm{C}-\mathrm{N}$ system $(\mathrm{N}-\mathrm{B}-\mathrm{N})$ and the $\mathrm{C}=\mathrm{N}$ system $(\mathrm{N}=$ $\mathrm{Q}=\mathrm{N})$ of the acrylic secondary amine. ${ }^{32}$ The bands at 506 and $695 \mathrm{~cm}^{-1}$ are characteristic of C-H out-of-plane ring bending. ${ }^{33}$

The bands observed in the region of 626 to $468 \mathrm{~cm}^{-1}$ are due to symmetric stretching in the early T-O-T group. ${ }^{34}$

The infrared spectra of the PANI- ${ }_{-}-\mathrm{HY}$ composite are shown in Figure 6. The emergence of characteristic zeolite bands can be noted from the incorporation of 5 wt \% HY. These characteristic bands include those located at 1175 and $1049 \mathrm{~cm}^{-1}$, which are attributed to stretching vibrations of $\mathrm{T}-\mathrm{O}-\mathrm{T}$ and $\mathrm{O}-\mathrm{T}-\mathrm{O}$ groups.

\section{UV-visible-NIR analysis}

The UV-visible spectra of deprotonated PANI- $\mathrm{HCl}$ and PANI-HY composites are superposed in Figure 7. The UV-visible-NIR spectra of 


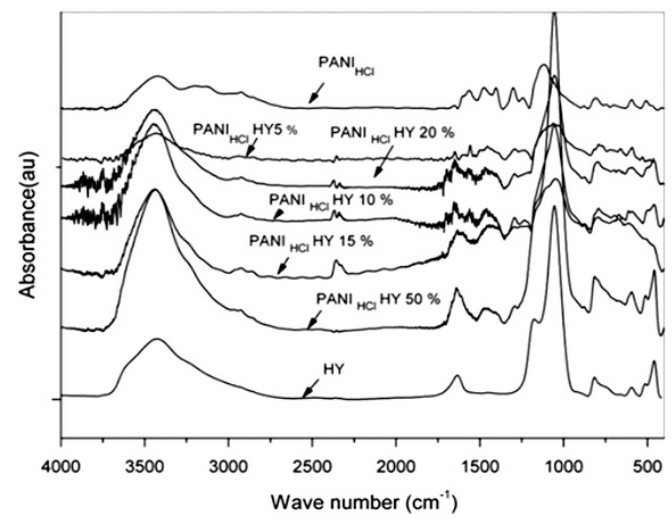

Figure 6 Infrared spectra of the PANI-HCl compared with PANI-HCl-HY (5, 10, 15, 20 and 50 wt \%) composites.

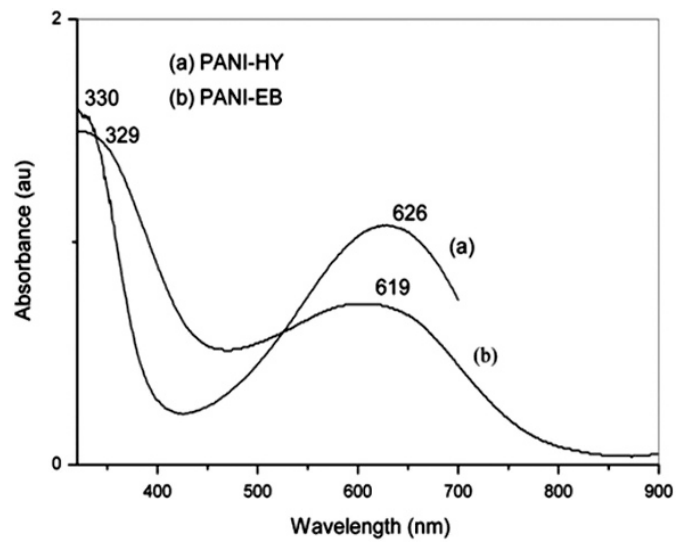

Figure 7 Ultraviolet (UV)-visible-NIR spectra of the (a) deprotonated $\mathrm{PANI}-\mathrm{HCl}$ and (b) deprotonated poly(aniline)/zeolite (PANI-HY) composites.

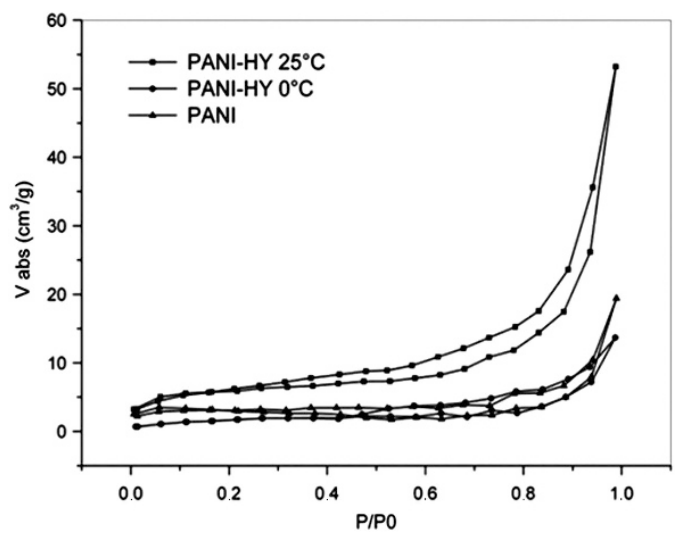

Figure 8 Nitrogen adsorption-desorption isotherm of composites poly(aniline)/zeolite (PANI-HY) and PANI.

the deprotonated PANI- $\mathrm{HCl}$ and deprotonated PANI-HY composite show two absorption maxima in $N$-methyl-2-pyrrolidone. The UVvisible-NIR spectrum of the PANI $_{-\mathrm{HCl}}$ base consists of bands at 330 and $620 \mathrm{~nm}$. The band at $330 \mathrm{~nm}$ is attributed to the electronic transition, and the band at $620 \mathrm{~nm}$, related to the exciton band, is attributed to a charge transfer from the highest occupied energy level, centered on the quinoid ring. In the UV-visible-NIR spectra of

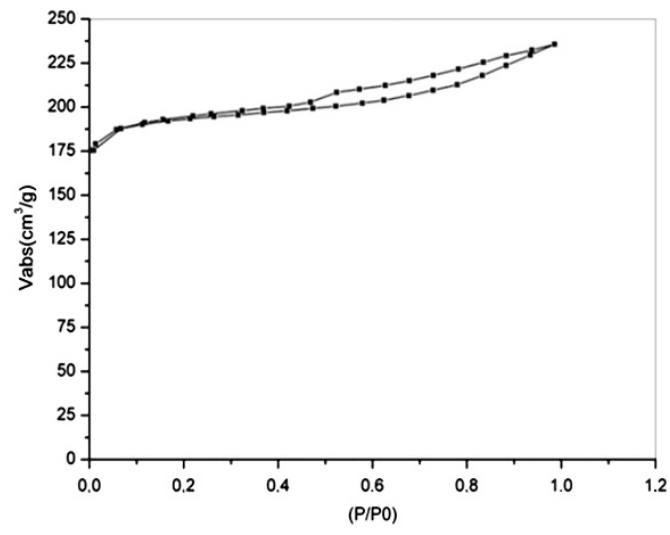

Figure 9 Nitrogen adsorption isotherm of zeolite HY.

Table 1 The specific surfaces of different materials according to the BET model

\begin{tabular}{lcccc}
\hline Samples & HY & PANI-HCl & PANI-HY, O ${ }^{\circ} \mathrm{C}$ & PANI-HY, 25 ${ }^{\circ} \mathrm{C}$ \\
\hline $\mathrm{S}_{\mathrm{BET}}\left(\mathrm{m}^{2} \mathrm{~g}^{-1}\right)$ (BET) & 567.67 & 6.22 & 6.50 & 16.78
\end{tabular}

Abbreviations: BET, Brunauer, Emmett and Teller method; PANI-HY, poly(aniline)/zeolite.

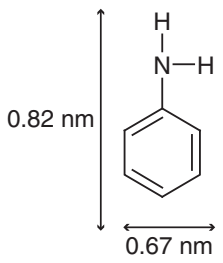

Figure 10 Size of aniline.

PANI-HY, two electronic bands were observed at 329 and $619 \mathrm{~nm}$. These bands originated from the transitions of benzene rings and quinoid exciton bands, respectively. ${ }^{35}$

\section{Porosity characterization}

In the $\mathrm{N}_{2}$ adsorption-desorption isotherms at very low $P / P_{0}$, the isotherm of the sample follows type II, described in Figure 8. The nature of isotherm of the HY zeolite is type IV, as shown in Figure 9, although no sharp capillary condensation was observed. The gradual increase in $\mathrm{N}_{2}$ uptake in this region could be attributed to multilayered adsorption, which is encountered when the adsorbent is nonporous or macroporous. The inflection point of the isotherm indicates the formation of a monolayer on the surface of adsorbent. When the relative pressure is greater than that of the monolayer, the adsorbed layer thickens to form multilayers. ${ }^{36}$

In Table 1, BET surface areas of different samples are given. BET surface area for samples PANI-HY at $0{ }^{\circ} \mathrm{C}$ is comparable with those of PANI- ${ }_{\mathrm{HCl}}$. The results revealed a decrease in specific surface area of both types of zeolites according to the BET method, which indicates effective formation of PANI.

It also appears that the HY zeolite was covered by PANI, because the surface area decreased by roughly $99 \%$. So there is a clogging of 
pores because of the in situ polymerization of aniline clogs zeolite pores. The size of an aniline molecule is shown in Figure 10.

The crystal lattice of HY zeolite consists of cells, each of which contain 192 tetrahedral-hexagonal prisms with diameters from 2.5 to $2.6 \AA$, sodalite cavities ( $\beta$ cages) with diameters from 5 to $6 \AA$, and $\alpha$ cage of $13 \AA$ diameter. Owing to the kinetic diameter of aniline, aniline was observed to adsorb inside $\alpha$ cage and clog the pores of the hexagonal prisms and sodalite cages.

An adsorption mechanism for in situ polymerization of aniline into HY zeolite is proposed in Figure 11. Interactions between the zeolite and aniline may have resulted from the strong acidity of the zeolite and the alkaline character of aniline.

\section{$\mathrm{X}$-ray diffraction measurements}

The characteristic peaks of HY zeolite were observed at $2 \theta=9.85^{\circ}$, $22.4^{\circ}$ and $30.0^{\circ}$ respectively. The presence of these peaks in the XRD pattern recorded for the PANI-HY composite confirms the presence of HY. The intensity of peaks in the X-ray pattern can be influenced

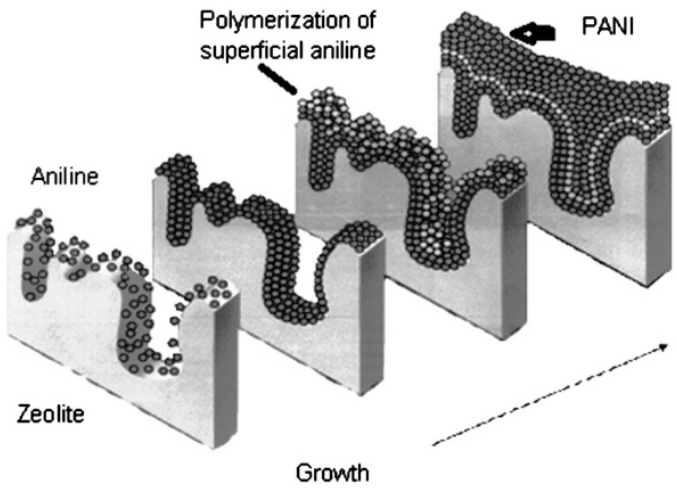

Figure 11 Mechanism of aniline adsorption into the zeolite.
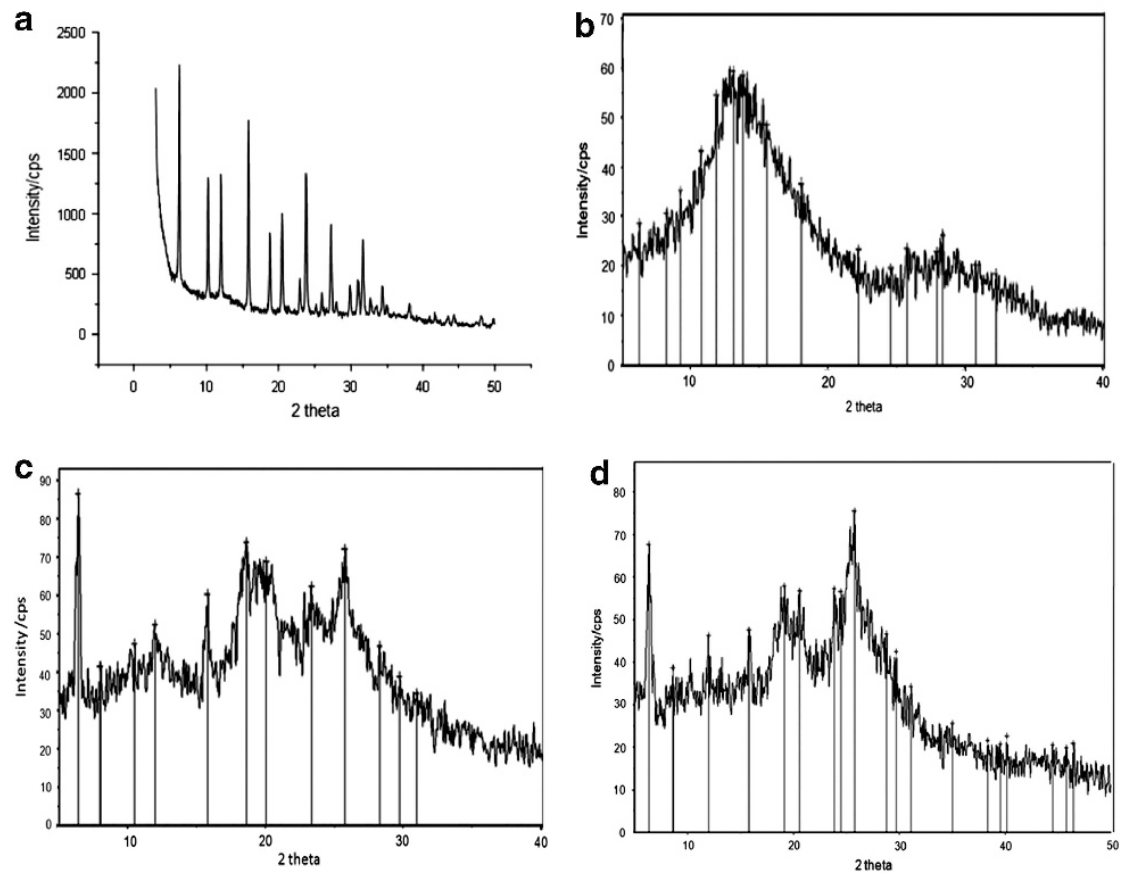

Figure 12 X-ray diffractograms of the (a) $\mathrm{HY}$ zeolite, (b) PANI- $\mathrm{HCl}$ and (c) PANI zeolite $\mathrm{HY}$ composites at $\mathrm{O}^{\circ} \mathrm{C}$ and $(\mathbf{d})$ at $25^{\circ} \mathrm{C}$. by the degree of crystallinity or by the order of PANI chains in the composite structure. According to the plot in Figure 12, the X-ray pattern of PANI suggests a relatively amorphous structure, but encapsulation of PANI in the HY channels significantly improves the alignment and arrangement of PANI chains. This alignment results in an increase in the intensity of the peaks related to the composite. X-ray powder diffraction analysis demonstrated that the crystallinity of HY zeolite in the composite is the same as that in the untreated HY.

\section{Morphology analyses}

The micrographs in Figure 13 show the formation of agglomerate particles of different sizes. Disorder in the particle size distribution is less pronounced because of the formation of deformed PANI-HY aggregates at $25^{\circ} \mathrm{C}$. There is a wide size distribution of particles formed during the polymerization of PANI-HY at $0{ }^{\circ} \mathrm{C}$.

According to the micrographs given in Figure 14, there is a clear evolution of the morphology based on the content of incorporated HY zeolite.

\section{Conductivity measurements}

Electrical conductivity at room temperature. The results of the electrical conductivity measurements at room temperature are summarized in Table 2. Electrical characterization of the processed composites indicates that the PANI-HY composite has a higher conductivity at $0{ }^{\circ} \mathrm{C}$ than at $25^{\circ} \mathrm{C}$. Meanwhile, for the dispersed $\mathrm{HY}$ zeolite in PANI- $\mathrm{HCl}$ the resulted PANI- $\mathrm{HCl}^{-} \mathrm{HY}$ composites indicated a decrease in conductivity with additional HY zeolite.

Electrical conductivity vs temperature. The conduction mechanisms for conducting polymers have been investigated using various models related to the interdependence of temperature and conductivity. Moreover, the temperature dependence of the conductivity of PANI 

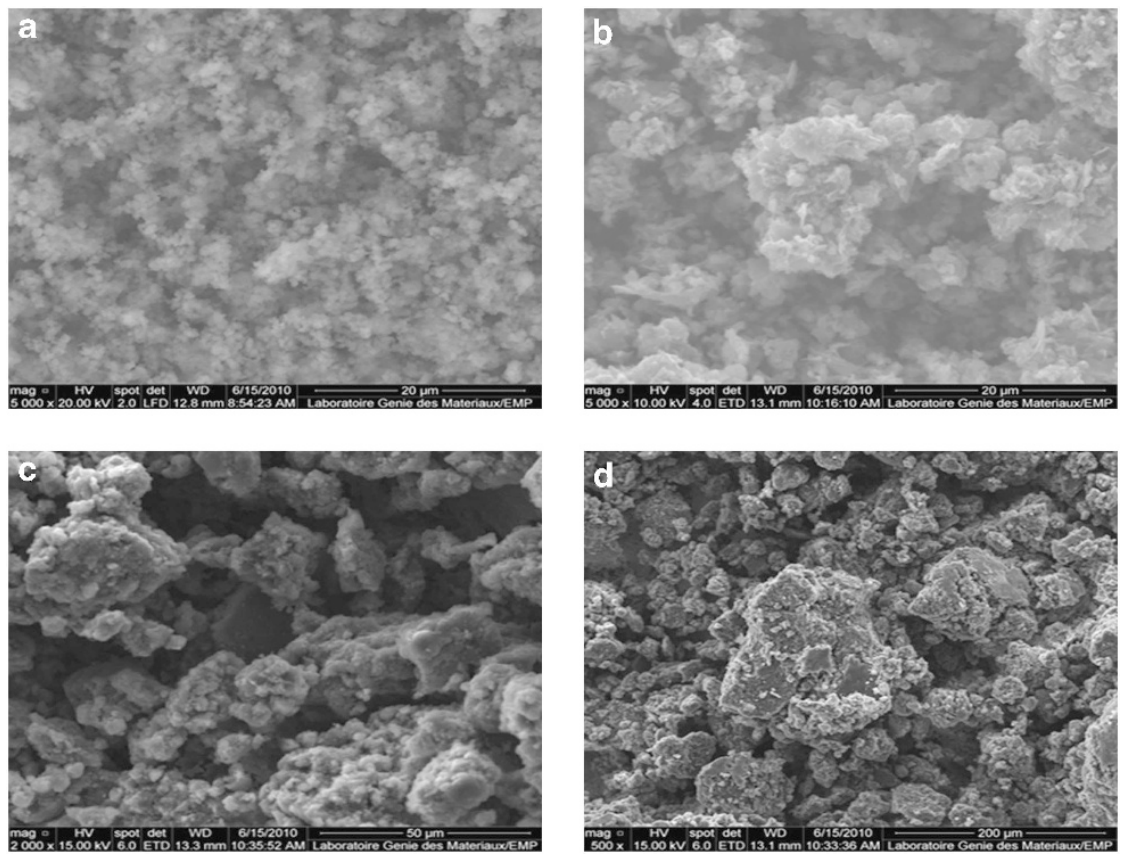

Figure 13 Micrograph of zeolite HY (X 5000) (a), PANI-HY composite at $25^{\circ} \mathrm{C}$ (X 5000) (b), and PANI-HY composite at $0^{\circ} \mathrm{C}(\mathrm{X} 2000, \mathrm{X} 500)(\mathbf{c}, \mathbf{d})$.
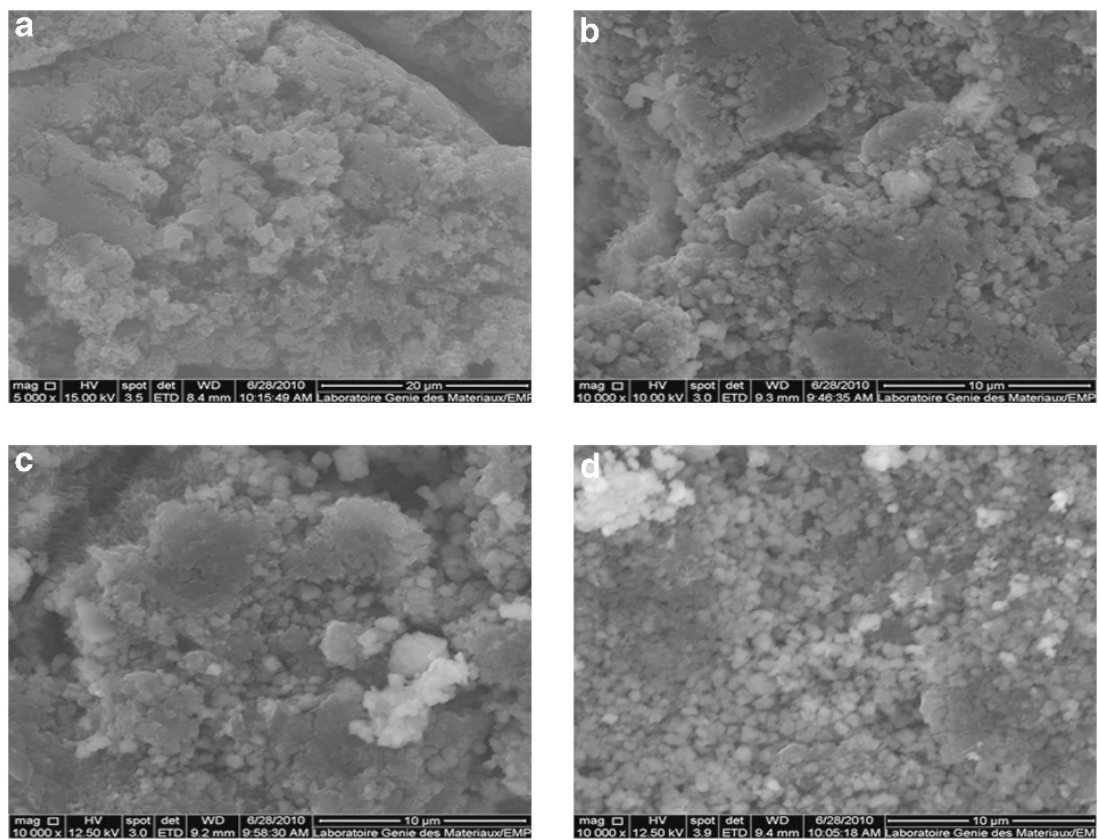

Figure 14 Micrograph of PANI-HCl (X 5000) (a), PANI-HCl-HY 15\% (X 5000) (b) PANI-HCl-HY 20\% (X 5000) (c) and PANI-HCl-HY50\% (X 10 000) (d).

and PANI-HY composites can be expressed according to the following variable-range hopping model proposed by Mott:

$$
\sigma=\sigma_{0} e^{-\left(\frac{T o}{T}\right)^{\gamma}}
$$

where $\sigma_{0}$ is the high temperature limit of conductivity and $T_{0}$ is Mott's characteristic temperature, which is associated with the required energies of charge carriers. The model assumes a granular metal-type structure in which electricity is conducted by charge carriers that tunnel through insulating barriers between conductive grains. ${ }^{37}$
The exponent $\gamma=1 /(1 \pm \mathrm{d})$ indicates the dimensions of the conducting medium. The possible values of $\gamma$ are $1 / 4,1 / 3$ and $1 / 2$ for three-, two- and one-dimensional systems, respectively. The bestfit value of $\gamma$ is obtained by linear regression analysis. ${ }^{38}$

Electrical conductivity vs temperature for PANI- $\mathrm{HCl}$. Strong coherence between chains allows charge carriers to hop between chains, resulting in three-dimensional variable-range hopping. Charge 
Table 2 The electrical conductivity of PANI, zeolite HY and different composites at room temperature

\begin{tabular}{lc}
\hline Samples & $\sigma\left(\mathrm{scm}^{-1}\right) \times 10^{4}$ \\
\hline Zeolite HY & 0.00822 \\
PANI-HCl & 106 \\
PANI-HY à $25^{\circ} \mathrm{C}$ & 0.737 \\
PANI-HY à 0 ${ }^{\circ} \mathrm{C}$ & 77.4 \\
PANI-HCl dedoped & 0.000019 \\
PANI-HCl- HY 5\% & 12.6 \\
PANI-HCI-HY 10\% & 10.4 \\
PANI_HCl-HY 15\% & 8.57 \\
PANI-HCI-HY 20\% & 6.57 \\
PANI-HCI-HY 50\% & 2.96 \\
\hline
\end{tabular}

Abbreviation: PANI-HY, poly(aniline)/zeolite.

The higher values of electrical conductivity are indicated in bold.

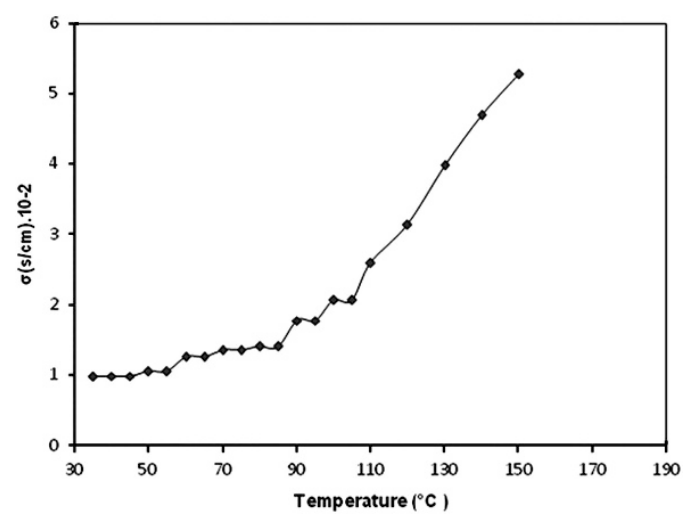

Figure 15 Temperature dependence of electrical conductivity for PANI-HCl.

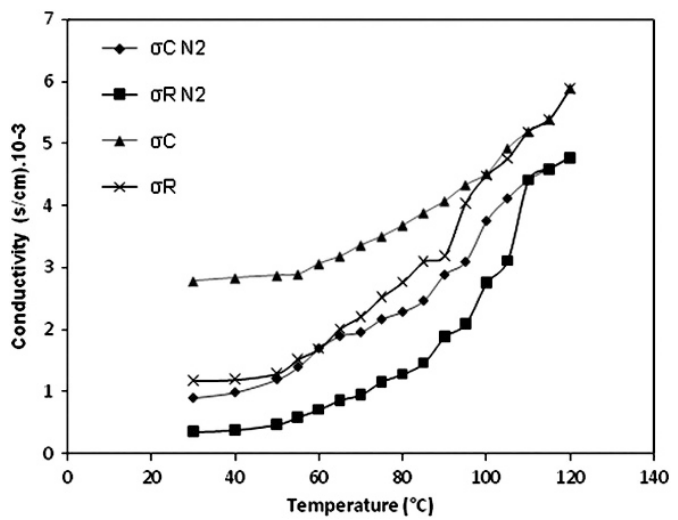

Figure 16 Temperature dependence of electrical conductivity in air and $\mathrm{N}_{2}$ for poly(aniline)/zeolite (PANI-HY).

carriers can also hop between particles or fibrils in the PANI sample by three-dimensional variable-range hopping.

The three-dimensional variable-range hopping model can be expressed as: ${ }^{39}$

$$
\sigma=\sigma_{0} e^{-\left(\frac{T_{0}}{T}\right)^{0.25}}
$$

This expression shows the temperature dependence of conductivity for PANI- ${ }_{\mathrm{HCl}}$, where $T_{0}=5496663.37 \mathrm{~K}$ and $=1224.147 \mathrm{~s} \mathrm{~cm}^{-1}$.

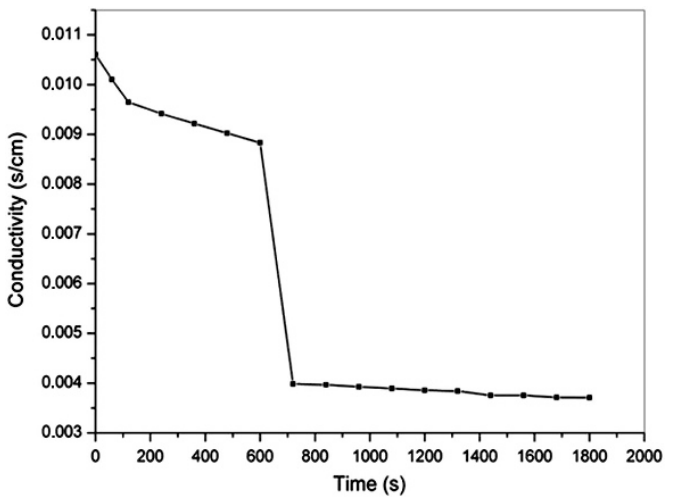

Figure 17 Time dependence of electrical conductivity on carbon dioxide $\left(\mathrm{CO}_{2}\right)$ for PANI-HCI.

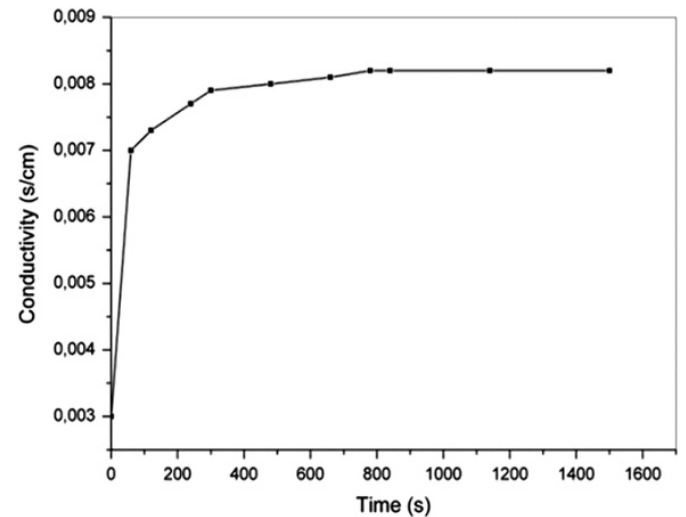

Figure 18 Time dependence of electrical conductivity in the presence of carbon dioxide $\left(\mathrm{CO}_{2}\right)$ for poly(aniline)/zeolite (PANI-HY).

Electrical conductivity vs temperature for PANI-HY in air and $\mathrm{N}_{2}$ gases. As shown in Figures 15 and 16, electrical conductivity increases with temperature under various environments. During the heating $\left(\sigma_{\mathrm{H}}\right)$ and cooling $\left(\sigma_{\mathrm{C}}\right)$ stages, a weaker dependence of electrical conductivity on temperature may be due to moisture present in PANI-HY. A possible reason for higher conductivity in air compared with $\mathrm{N}_{2}$ milieu, which resulting following to the may be interactions with $\mathrm{O}_{2}$ at the active site; another possible cause is the presence of moisture in air. ${ }^{40}$

The fit verifies the model: ${ }^{41,42}$

$$
\sigma=\sigma_{0} e^{-\left(\frac{T_{0}}{T}\right)^{0.5}}
$$

where $\sigma_{0}=68.37 \mathrm{scm}^{-1}$ and $T_{0}=2815.176 \mathrm{~K}$.

\section{Detection of $\mathrm{CO}_{2}$}

A gas sensor is defined as a component in which at least one of its physical properties changes when the component is subjected to a change in gaseous environment. Generally, a sensor consists of two main components: a sensing element and a transducer. The sensing element reacts with gaseous species, and the transducer translates the results of this reaction to an easily measurable signal (electrical or optical). 


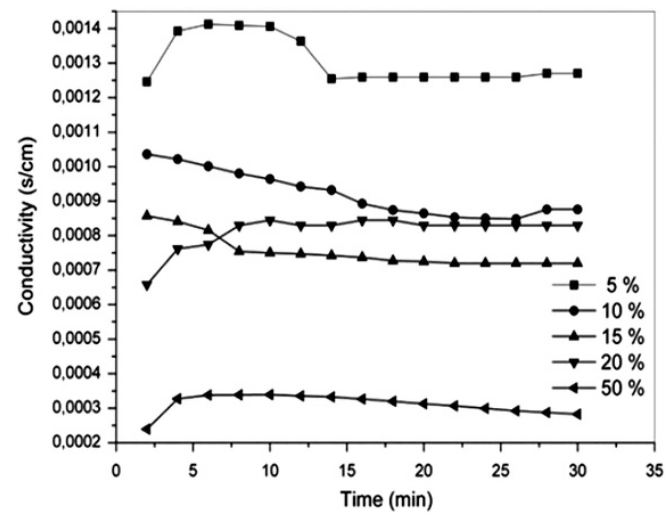

Figure 19 Time dependence of electrical conductivity in the presence of carbon dioxide $\left(\mathrm{CO}_{2}\right)$ for poly(aniline)/zeolite (HY-PANI) composites obtained by physical mixture root.

Detection mechanisms of $\mathrm{CO}_{2}$, which is acidic by nature, are rarely described in the literature. ${ }^{43}$ In Figure 17, the electrical conductivity decreases on exposure to $\mathrm{CO}_{2}$ before becoming constant with time. In Figure 18, the electrical conductivity increases with $\mathrm{CO}_{2}$ before becoming constant; this behavior can be attributed to $\mathrm{CO}_{2}$ capture by the PANI- ${ }_{-} \mathrm{HCl}^{-} \mathrm{HY}$ composite. The short response time may be due to the acidic character of $\mathrm{CO}_{2}$.

The stability and fast response led to a study of the material's behavior with respect to time. A linear response is observed as time increases, leading to saturation of the composite. This response can be attributed to a decrease in the available free volume of the composite. In addition, electron delocalization increases with an increase in gas adsorption by the composite.

The form of PANI used to detect $\mathrm{CO}_{2}$ is the ES, which is partially doped by $\mathrm{HCl}$ following the reaction with $\mathrm{CO}_{2}$. The resulting increase in conductivity may be a consequence of doping. When PANI- $\mathrm{HCl}$ is used, the reaction between $\mathrm{PANI}_{-\mathrm{HCl}}$ and $\mathrm{CO}_{2}$ causes the de-doping of PANI, which decreases the conductivity. The use of $\mathrm{PANI}_{-\mathrm{HCl}^{-} \mathrm{HY}}$ leads to an increase in the conductivity ' $\sigma$ '. This increase is due to $\mathrm{CO}_{2}$ sequestration by the zeolite, which increases the zeolite's acidic nature and results in post-doping.

The plots of electrical conductivity versus time in Figure 19 show a trend similar to that of composites that vary by HY zeolite content. This trend is more pronounced for composites with 20 and 50 wt \% of HY.

\section{CONCLUSIONS}

In summary, we have demonstrated an efficient in situ polymerization method to synthesize a conducting PANI-HY composite. The method utilizes the oxidative polymerization of aniline with APS in an aqueous suspension of HY zeolite without added acid. The PANI-HY composite exhibits a lower conductivity by $7.74 \times 10^{-3}-10^{-2} \mathrm{scm}^{-1}$ when compared with PANI doped by $\mathrm{HCl}$. PANI- ${ }_{-} \mathrm{HCl}^{-} \mathrm{HY}$ synthesized as a new composite system by physical mixing is sensitive toward $\mathrm{CO}_{2}$ gas. In fact, the conductivity of these composite increases with exposure to $\mathrm{CO}_{2}$; this behavior is well-observed and described as an interaction between PANI and acidic $\mathrm{CO}_{2}$ molecules. The rapid response time of $\mathrm{CO}_{2}$ capture provides evidence of the efficiency of the new composite. More investigations regarding the threshold concentration of gas and the precision of the measurement devices should be performed to improve the sensitivity and the response time of the composite.
1 Malinauskas, A. Chemical deposition of conducting polymer. Polymer (Guildf) 42, 3957-3972 (2001).

2 Ohtani, A., Abe, M. \& Ezoe, M. Synthesis and properties of high-molecular-weight soluble polyaniline and its application to the $4 \mathrm{mb}$-capacity barium ferrite floppy disks antistatic coating. Synthet. Metal. 55-57, 3696-3701 (1993).

3 Davies, S. J., Ryan, T. G., Wilde, C. J. \& Beyef, G. Processable forms of conductive polyaniline. Synthet. Metal. 69, 209-210 (1995).

4 Samrana, K., Vazid, A., Zulfequar, M., Mazharul Haq, M. \& Husain, M. Electrical, thermal and spectroscopic studies of Te doped polyaniline. Curr. Appl. Phys. 7, 68-75 (2007).

$5 \mathrm{Kim}$, J., Kwon, S. \& Ihm, D. Synthesis and characterization of organic soluble polyaniline prepared by one-step emulsion polymerization. Curr. Appl. Phys. 7, 205-210 (2007).

6 Rubinger, C. P. L., Costa, L. C., Faez, R., Martins, C. R. \& Rubinger, R. M. Hopping conduction on PAni/PSS blends. Synthet. Metal. 159, 523-527 (2009).

7 Srivastava, A., Singh, V., Chandra, A., Witte, K., Scherer, U. W. \& Singh, T. V. Electrical conductivity studies of swift heavy ion modified PVC and PVC-PANI composite. Nuclear Instruments Methods Phys. Res. B 245, 277-280 (2006).

8 Mo, Z., Zhao, Z., Chen, H., Niu, G. \& Shi, H. Heterogeneous preparation of cellulosepolyaniline conductive composites with cellulose activated by acids and its electrical properties. Carbohydr. Polymers 75, 660-664 (2009).

9 Banerjee, S. \& Kumar, A. J. Dielectric behavior and charge transport in polyaniline nanofiber reinforced PMMA composites. J. Phys. Chem. Solids 71, 381-388 (2010).

10 Oliveira, M. A. S., Mora, J. J. \& Faez, R. Impedance studies of poly(methylmethacrylate-co-acrylic acid) doped polyaniline films on aluminum alloy. Prog. Org. Coating 65, 348-356 (2009).

11 Vulpe, S., Nastase, F., Nastase, C. \& Stamatin, I. PAN-PAni nanocomposites obtained in thermocentrifugal fields. Thin Solid Films 495, 113-117 (2006).

12 Inamuddin Khan, A. A. Preparation, physico-chemical characterization, analytical applications and electrical conductivity measurement studies of an 'organic-inorganic' composite cation-exchanger: polyaniline Sn(IV) phosphate. React. Funct. Polym. 66, 1649-1663 (2006).

13 Khan, A. A. \& Paquiza, L. Electrical behavior of conducting polymer based 'polymericinorganic' nanocomposite: polyaniline and polypyrrole zirconium titanium phosphate. Synthet. Metal. 161, 899-905 (2011).

14 Wong, K. H., Pickering, S. J. \& Rudd, C. D. Recycled carbon fiber reinforced polymer composite for electromagnetic interference shielding. Composites: Part A 41, 693-702 (2010).

15 Papathanassiou, A. N., Grammatikakis, J., Sakellis, I., Sakkopoulos, S., Vitorats, E. \& Dalas, E. Themal degradation of the dielectric relaxation of $10-90 \%$ (w/w) zeolite-conducting polypyrrole composites. Synthet. Metal. 150, 145-151 (2005).

16 Yanga, L. Y. \& Liaua, W. B. Environmental responses of polyaniline inverse opals: application to gas sensing. Synthet. Metal. 160, 609-614 (2010).

17 Yan, X. B., Han, Z. J., Yang, Y. \& Tay, B. K. NO 2 gas sensing with polyaniline nanofibers synthesized by a facile aqueous/organic interfacial polymerization. Sensors Actuators B 123, 107-113 (2007).

18 Sadek, A. Z., Wlodarski, W., Shin, K., Kaner, R. B. \& Kalantar-zadeh, K. A polyaniline/ $\mathrm{WO}_{3}$ nanofiber composite-based $\mathrm{ZnO} / 64^{\circ} \mathrm{YX} \mathrm{LiNbO}_{3} \mathrm{SAW}$ hydrogen gas sensor. Synthet. Metal. 158, 29-32 (2008).

19 Du, Z., Li, C., Li, L., Yu, H., Wang, Y. \& Wang, T. Ammonia gas detection based on polyaniline nanofibers coated on interdigitated array electrodes. J. Mater. Sci. Mater. Electron 22, 418-421 (2011).

20 Bai, H. \& Shi, G. Gas sensors based on conducting polymers. Sensors 7, 267-307 (2007).

21 Kalendová, A., Veselý, D., Sapurina, I. \& Stejskal, J. Anticorrosion efficiency of organic coatings depending on the pigment volume concentration of polyaniline phosphate. Prog. Org. Coating 63, 228-237 (2008).

22 Samui, A. B. \& Phadnis, S. M. Polyaniline-dioctyl phosphate salt for corrosion protection of iron. Prog. Org. Coating 54, 263-267 (2005).

23 Javed, A., Ufana, R., Ashraf, S. M. \& Sharif, A. Corrosion-protective performance of nano polyaniline/ferrite dispersed alkyd coatings. J. Coat. Technol. Res. 5, 123-128 (2008).

24 Armelin, E., Pla, R., Liesa, F., Ramis, X., Iribarren, J. I. \& Aleman, C. Corrosion protection with polyaniline and polypyrrole as anticorrosive additives for epoxy paint. Corros. Sci. 50, 721-728 (2008).

25 Tierrablanca, E., García, J. R., Roman, P. \& Silva, R. C. Biomimetic polymerization of aniline using hematin supported on halloysite nanotubes. Appl. Catal. A 381, 267-273 (2010).

26 Marjanovic, G. C., Dondur, V., Milojevic, M., Mojovic, M., Mentus, S., Radulovic, A., Vukovic, Z. \& Stejskal, J. Synthesis and characterization of conducting self-assembled polyaniline nanotube/zeolite nanocomposite. Langmuir 25, 3122-3131 (2009).

27 Bein, T. \& Enzel, P. Inclusion polymerization and doping in zeolite channel: polyaniline. Mol. Cryst. Liq. Cryst 181, 315-324 (1990).

28 Seoudi, R., Kamal, M., Shabaka, A. A., Abdelrazek, E. M. \& Eisaa, W. Synthesis, characterization and spectroscopic studies of CdS/polyaniline core/shell nanocomposite. Synthet. Metal. 160, 479-484 (2010).

29 Cuentas-Gallegos, A. K. \& Ǵomez-Romero, P. Triple hybrid materials: a nove concept within the field of organic-inorganic hybrids. J. Power Sources 161, 580-586 (2006).

30 Chen, H., Matsumoto, A., Nishimiya, N. \& Tsutsumi, K. Preparation and characterization of TiO2 incorporated Y-zeolite. Physicochem Eng Aspects 157, 295-305 (1999). 
31 Datka, J., Gil, B., Domagala, T. \& Marek, K. G. Homogeneous OH group in dealuminated HY zeolite studied by spectroscopy. Microporous Mesoporous Mat. 47, 61-66 (2001).

32 Virji, S., Kojima, R., Fowler, J. D., Villanueva, J. G., Kaner, R. B. \& Weiller, B. H. Polyaniline nanofiber composites with amines: novel materials for phosgene detection. Nano. Res. 2, 135-142 (2009).

33 Jayamurugan, P., Mariappan, R., Ponnuswamy, V., Manikandan, H., Asokan, S. \& Saravanan, S. High-PL efficiency of polyaniline using various dopants. Optik Int. J. Light Electron Opt. 122, 2083-2085 (2011).

34 Anunziat, O. A., Gómez Costa, M. \& B.Martínez, M. L. Interaction of water and aniline adsorbed onto Na-AIMCM-41 and Na-AISBA-15 catalysts as hosts materials. Catal. Today 133-135, 897-905 (2008).

35 Karim, M. R., Limb, K. T., Lee, M. S., Kim, K. \& Yeum, J. H. Sulfonated polyanilinetitanium dioxide nanocomposites synthesized by one-pot UV-curable polymerization method. Synthet. Metal. 159, 209-213 (2009).

36 Nandi, M., Gangopadhyay, R. \& Bhaumik, A. Mesoporous polyaniline having high conductivity at room temperature. Microporous Mesoporous Mat. 109, 239-247 (2008)
37 Vitoratos, E., Sakkopoulos, S., Dalas, E., Malkaj, P. \& Anestis, C. D.C. conductivity and thermal aging of conducting zeolite/polyaniline and zeolite/polypyrrole blends. Curr. Appl. Phys 7, 578-581 (2007).

38 Shao, L., Qiua, J., Liu, M., Feng, H., Zhang, G., Lü, S. \& Qin, L. Preparation and characterization of attapulgite/polyaniline nanofibers via self-assembling and graft polymerization. Chem. Eng. J. 161, 301-307 (2010).

$39 \mathrm{Li}$, J., Fang, K., Qiu, H., Li, S. \& Mao, W. Micromorphology and electrical property of the HCl-doped and DBSA-doped polyanilines. Synthet. Metal. 142, 107-111 (2004).

40 Chuapradit, C., Wannatong, L. R. \& Chotpattananont, D. Polyaniline/zeolite LTA composites and electrical conductivity response towards CO. Polymer (Elsevier) 46, 947-953 (2005)

41 Dalas, E., Vitoratos, E., Sakkopoulos, S. \& Malkaj, P. Polyaniline/zeolite as the cathode in a novel gel electrolyte primary dry cell. J. Power Sources 128, 319-332 (2004).

42 Vitoratos, E., Sakkopoulos, S., Dalas, E., Malkaj, P. \& Anestis, C. D. C.conductivity and thermal aging of conducting zeolite/polyaniline and zeolite/polypyrrole blends. Curr. Appl. Phys. 7, 578-58 (2007).

43 Neethirajan, S., Freund, M. S., Jayas, D. S., Shafai, C., Thomson, D. J. \& White, N. D. G. Development of carbondioxide (CO2) sensor for grain quality monitoring. Biosyst. Eng. 106, 395-404 (2010). 